\title{
The Interreg IV Italia-Austria "SeismoSAT" project: connecting seismic data centers via satellite
}

\author{
D. Pesaresi ${ }^{1}$, W. Lenhardt ${ }^{2}$, M. Rauch ${ }^{3}$, M. Živčic ${ }^{4}$, R. Steiner ${ }^{2}$, P. Fabris ${ }^{1}$, and M. Bertoni ${ }^{1}$ \\ ${ }^{1}$ OGS (Istituto Nazionale di Oceanografia e di Geofisica Sperimentale), Trieste, Italy \\ ${ }^{2}$ Zentralanstalt für Meteorologie und Geodynamik, Wien, Austria \\ ${ }^{3}$ Provincia Autonoma di Bolzano, Bolzano, Italy \\ ${ }^{4}$ Agencija Republike Slovenije za Okolje, Ljubljana, Slovenia \\ Correspondence to: D. Pesaresi (dpesaresi@inogs.it)
}

Received: 16 July 2013 - Revised: 1 April 2014 - Accepted: 1 May 2014 - Published: 6 June 2014

\begin{abstract}
Since 2002 OGS (Istituto Nazionale di Oceanografia e di Geofisica Sperimentale) in Udine (Italy), the Zentralanstalt für Meteorologie und Geodynamik (ZAMG) in Vienna (Austria), and the Agencija Republike Slovenije za Okolje (ARSO) in Ljubljana (Slovenia) are using the Antelope software suite as the main tool for collecting, analyzing, archiving and exchanging seismic data in real time, initially in the framework of the EU Interreg IIIA project "Trans-national seismological networks in the South-Eastern Alps" (Bragato et al., 2004, 2010). The data exchange has proved to be effective and very useful in case of seismic events near the borders between Italy, Austria and Slovenia, where the poor single national seismic networks coverage precluded a correct localization, while the usage of common data from the integrated networks improves considerably the overall reliability of real time seismic monitoring of the area (Fig. 1). At the moment the data exchange between the seismic data centers relies on their internet connections: this however is not an ideal condition for civil protection purposes, since the reliability of standard internet connections is poor. For this reason in 2012 the Protezione Civile della Provincia Autonoma di Bolzano in Bolzano (PCBZ, Italy), OGS, ZAMG subsidiary in Tirol (ZAMG Tirol) and ARSO joined in the Interreg IV Italia-Austria Project "SeismoSAT" (Progetto SeismoSAT, 2012) aimed in connecting the seismic data centers in real time via satellite. ARSO does not belong to the Interreg Italia-Austria region: for this reason ARSO joined the SeismoSAT project as an "associated partner", which, according to Interreg rules can not be funded. ARSO participation in the project is therefore at the beginning limited in benefiting only indirectly from
\end{abstract}

improvement in the robustness of the data exchange between the other data centers, while eventually fully taking part in the project if other sources of funding will be available. The project is in a preliminary phase: the general schema of the project, including first data bandwidth estimates and a possible architecture are here illustrated.

\section{Introduction}

The border region of Slovenia, Austria and Northeast Italy is seismically very active (Fig. 1) and has experienced several destructive earthquakes in the past. OGS, ZAMG and ARSO seismic networks are operating in the area supporting research, monitoring and alerting to local and national authorities. The example of recent strong earthquakes demonstrated that the integration of services provided by the neighboring networks is essential for a rapid and efficient intervention. At the moment the data exchange between the seismic data centers relies on their internet connections: this however is not an ideal condition for civil protection purposes, since the reliability of standard internet connections is poor. Generally internet connections can provide high bandwidth at relatively small cost, but could suffer of disruption of service in case of strong natural events like big earthquakes. Same is true for mobile GPRS/UMTS data links, where data bandwidth is even less. Satellite links, apart from the problem of antenna dislocation by strong earthquake, if provided with reliable power supply can provide more robust data connections. The SeismoSAT project will make use of satellite technology as 


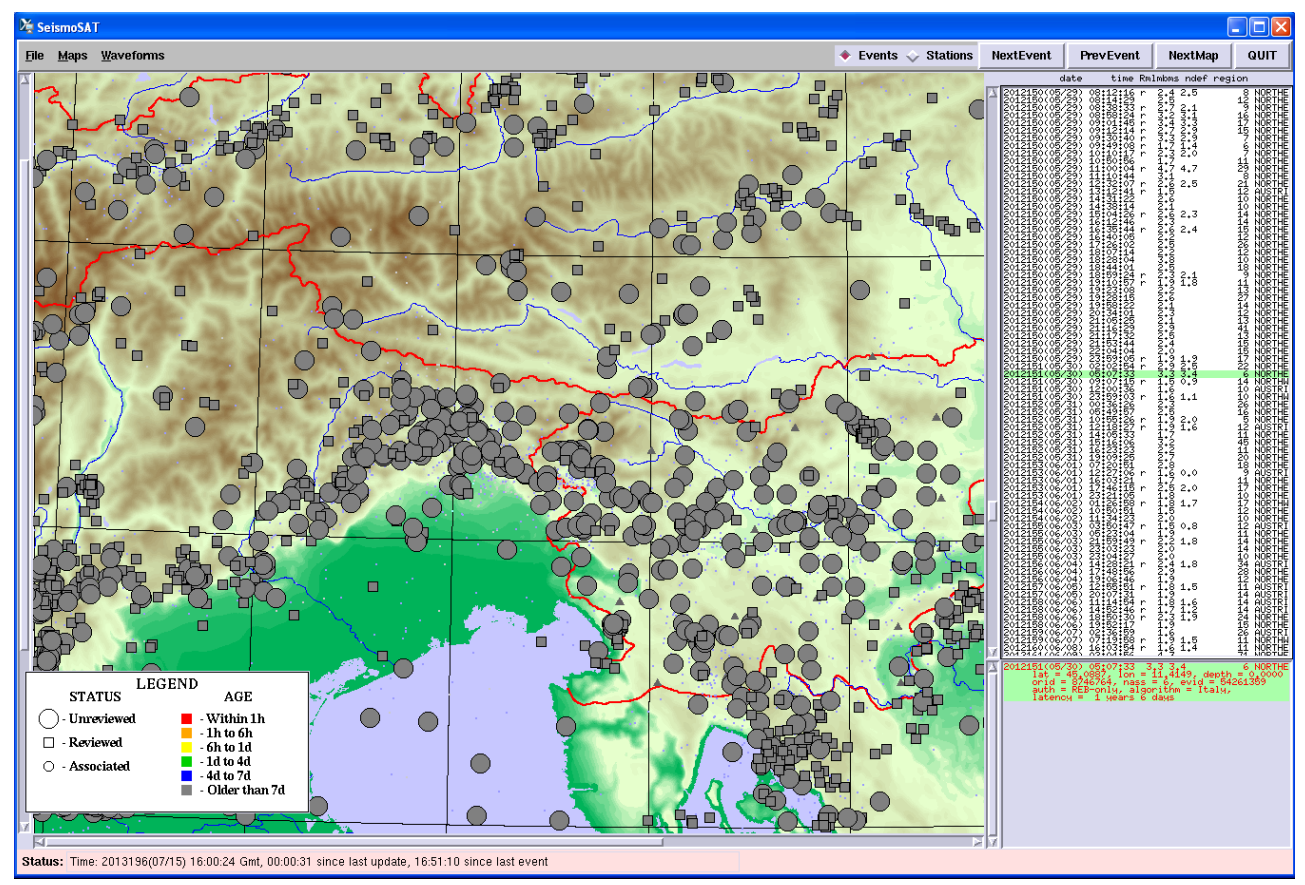

Figure 1. Seismicity map in the years 2011-2012 of the border region between Northeast Italy, Austria and Slovenia. In the map the events with magnitude $M_{\mathrm{L}}>1.5$ are shown. The plot is produced with the Antelope software.

back up for the primary internet data link between data centers.

\section{Networks and bandwidths}

A map of the seismic stations and the data centers involved in the SeismoSAT project is illustrated in Fig. 2.

Table 1 shows average data link bandwidth required by the seismic stations involved in the SeismoSAT project. The bandwidth has been measured with the "orbstat" program of the Antelope software suite (BRTT Antelope software, 1995). It collects data on bandwidth required by each acquisition channels of a seismic stations by multiplying the number of packets received per second by each channel per the packet size. The average is done over the period since the last software reboot: in this specific case over a period of over 3 months.

The average bandwidth of station list indicated in Table 1 is $2.46 \mathrm{Kbit} \mathrm{s}^{-1}$. This number is calculated on a normal seismic noise mode, where data compression is quite efficient, which is not true in case of seismic event. Variability in bandwidth required in Table 1 comes from different acquisition systems with different format/protocol used, different number of sensor used (only seismometer or seismometer coupled with accelerometer), various site quietness. As an example, station MOA and ARSA are very quite stations equipped only with seismometers ( 3 channels), while on the other side station BOSI is equipped with 2 sensors (6 channels) in a very noisy city environment.

In order to accomplish enough bandwidth for transmitting seismic data also in extraordinary conditions during a large earthquake, we fixed a bandwidth requirement of $8 \mathrm{Kbit} \mathrm{s}^{-1}$ per each seismic station. As an example, Steim compression level 1 basically guarantee a compression of a factor of 4 between full range and quite conditions by using firstdifferences 1 byte in quite conditions instead of 2 or 4 bytes in noisy conditions (SEED Reference Manual Version 2.4).

Total bandwidths required per network are then:

- OGS $120 \mathrm{Kbits}^{-1}$

- ZAMG $88 \mathrm{Kbits}^{-1}$

- PCBZ $48 \mathrm{Kbit} \mathrm{s}^{-1}$

Each data centre has to upload to the satellite network 2 copies of its network data, one for each of the other 2 data centers.

Total upload bandwidths required are therefore:

- OGS $240 \mathrm{Kbit} \mathrm{s}^{-1}$

- ZAMG $176 \mathrm{Kbits}^{-1}$

- PCBZ 96 Kbit s $^{-1}$

While download bandwidths required are:

- OGS $136 \mathrm{Kbits}^{-1}$ 


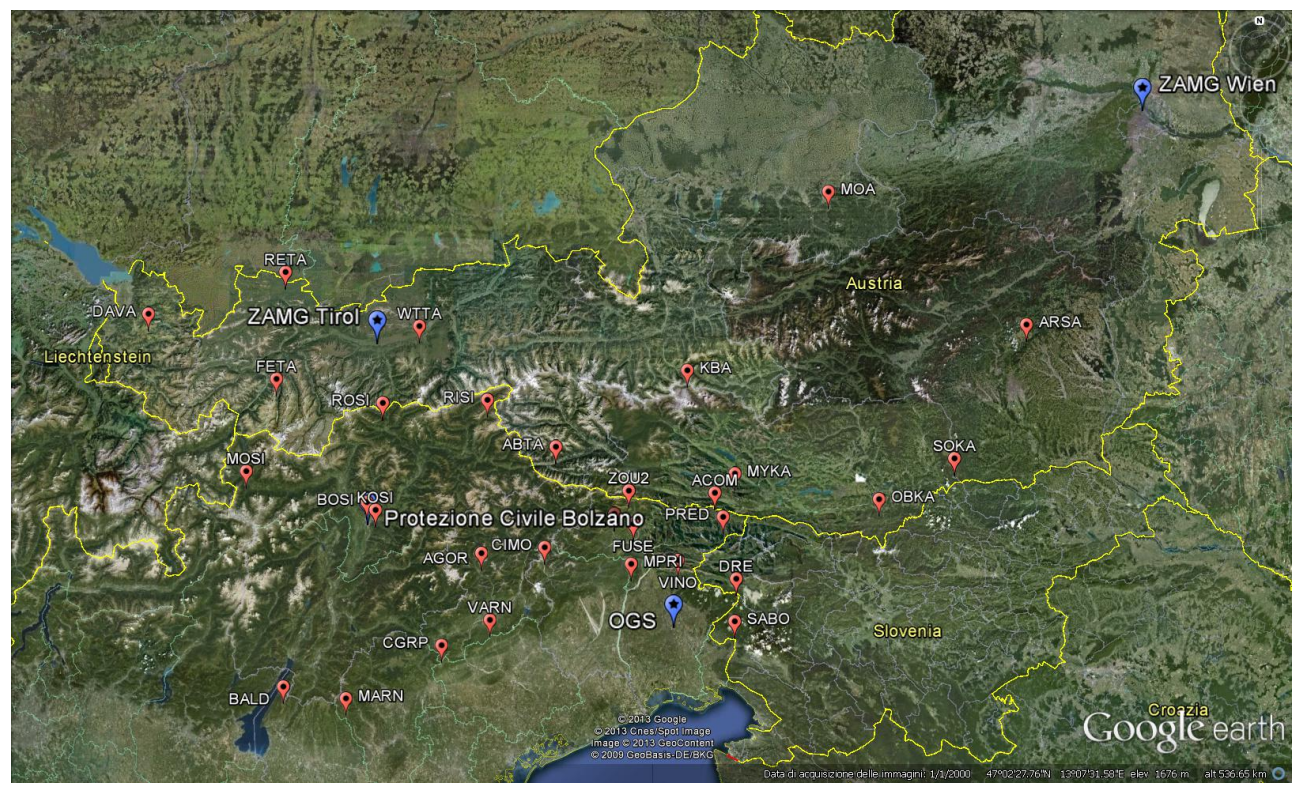

Figure 2. Map of seismic stations in red and data centers in blue involved in the SeismoSAT project.

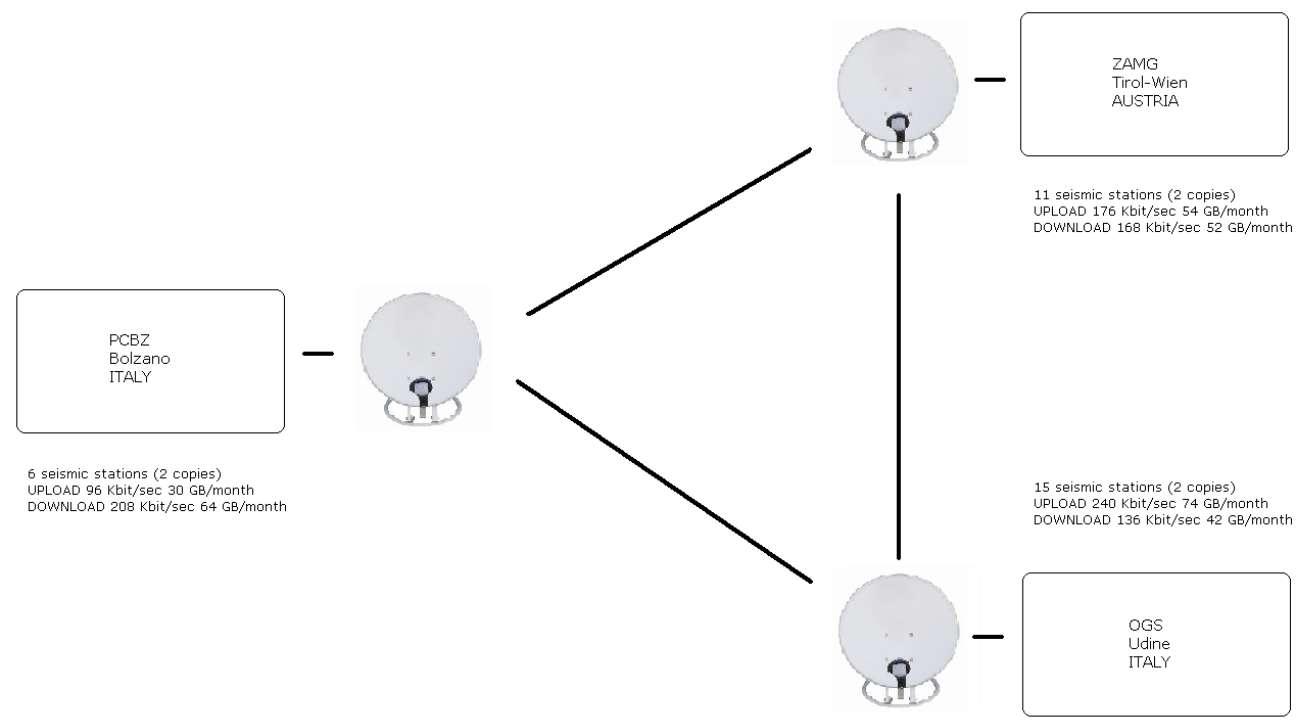

Figure 3. SeismoSAT schematic diagram with data bandwidth requirements.

- ZAMG $168 \mathrm{Kbits}^{-1}$

- PCBZ $208 \mathrm{Kbit} \mathrm{s}^{-1}$

Satellite contracts often includes "fair policy" limiting total amount of data transmitted per month. Therefore expected monthly data bandwidth for SeismoSAT are:

- OGS $74 \mathrm{~GB} /$ month upload, $42 \mathrm{~GB} /$ month download

- ZAMG $54 \mathrm{~GB} / \mathrm{month}$ upload, $52 \mathrm{~GB} / \mathrm{month}$ download

- PCBZ $30 \mathrm{~GB} /$ month upload, $64 \mathrm{~GB} /$ month download

\section{Project schematic}

The project schematic is illustrated in Fig. 3, with the total data bandwidth requirements per data centers.

The Antelope software suite has the capability to exchange data in real time among data centers: for this purpose the standard "orb2orb" software module is used. It uses a proprietary protocol and a point-to-point client/server architecture to exchange data. A more sophisticated version of this data exchange module is the software module named "orbxchange". "orbxchange" is a multithreaded version of "orb2orb" which supervises multiple "orb2orb" 
Table 1. Station list of Fig. 2 with bandwidth in Kbit s ${ }^{-1}$.

\begin{tabular}{|c|c|c|c|}
\hline Institute & Station code & Station name & $\begin{array}{c}\text { Bandwidth } \\
\left(\mathrm{Kb} \mathrm{s}^{-1}\right)\end{array}$ \\
\hline OGS & ACOM & Acomizza & 2.4 \\
\hline OGS & AGOR & Agordo & 2.1 \\
\hline OGS & BALD & Monte Baldo & 2.9 \\
\hline OGS & CGRP & Cima Grappa & 2.4 \\
\hline OGS & CIMO & Cimolais & 1.8 \\
\hline OGS & CLUD & Cludinico & 2.4 \\
\hline OGS & DRE & Drenchia & 3.0 \\
\hline OGS & FUSE & Fusea & 2.9 \\
\hline OGS & MARN & Marana & 3.5 \\
\hline OGS & MPRI & Monte Prat & 2.7 \\
\hline OGS & PRED & Cave del Predil & 3.3 \\
\hline OGS & SABO & Mt. Sabotino & 2.7 \\
\hline OGS & VARN & Col Varnada & 2.8 \\
\hline OGS & VINO & Villanova & 1.7 \\
\hline OGS & ZOU2 & Zouf Plan & 2.4 \\
\hline ZAMG & ABTA & Abfaltersbach & 2.7 \\
\hline ZAMG & ARSA & Arzberg & 1.2 \\
\hline ZAMG & DAVA & Damuels & 1.5 \\
\hline ZAMG & FETA & Feichten & 2.4 \\
\hline ZAMG & KBA & Koelnbreinsperre & 1.5 \\
\hline ZAMG & MOA & Molln & 1.2 \\
\hline ZAMG & MYKA & Terra Mystika & 2.4 \\
\hline ZAMG & OBKA & Obir.Austria & 2.5 \\
\hline ZAMG & RETA & Reutte & 2.6 \\
\hline ZAMG & SOKA & Soboth & 2.5 \\
\hline ZAMG & WTTA & Wattenberg & 1.8 \\
\hline PCBZ & ABSI & Aberstükl & 2.8 \\
\hline PCBZ & BOSI & Bozen/ZS Zentrale & 4.0 \\
\hline PCBZ & KOSI & Kohlern/Titschen & 2.7 \\
\hline PCBZ & MOSI & Großmontoni/Vinschgau & 2.7 \\
\hline PCBZ & RISI & Rein in Taufers/Ahrntal & 2.6 \\
\hline PCBZ & ROSI & Roßkopf/Sterzing & 2.6 \\
\hline
\end{tabular}

copies specified in a parameter file; it has the option of switching to alternate servers when no data is being copied from the primary. A distributed real time seismic database has been so established by connecting ZAMG, CRS/OGS, DST/UTS and ARSO Antelope servers with "orbxchange" modules (Horn et al., 2007). A test of the above described "orbxchange" features has been conducted artificially shutting down the Antelope servers and/or the data links between them: the results in the data coverage of the multiple copies of the distributed database showed an improvement in data availability that will be very useful for the institutional activities (like rapid earthquake location with magnitude estimation) of the institutions involved, but moreover its natural extension will be in more mission critical applications, like in public civil protection applications and rapid notification of inherent authorities like in the SeismoSAT Project.

\section{Conclusions}

Satellites at OGS are already in use to connect seismic stations to the data centre in Udine; for the SeismoSAT Project financial costs of the following satellite providers in the Interreg area will be investigated based on the above illustrated technical characteristics: EutelSat, Astra, Hellasat and possibly others.

Acknowledgements. The authors wish to thank the Interreg ItaliaAustria (2007) Authority for the financial support on the ERDF (2000) Fund and all the colleagues of OGS, ZAMG and Protezione Civile della Provincia Autonoma di Bolzano not mentioned here for their support to the SeismoSAT Project.

\section{References}

Bragato, P. L., Costa, G., Fitzko, F., Horn, N., Priolo, E., Kobal, M., Suhadolc, P., and Živčić, M.: The INTERREG IIIA Project: "Trans-National Seismological Networks in the South-eastern Alps", ESC XXIX General Assembly, Potsdam, Germany, 1317 September 2004, 2004.

Bragato, P. L., Costa, G., Horn, N., Pahor, J., Pesaresi, D., Lenhardt, W., and Živčić, M.: The usage of Antelope for acquiring end exchanging data in South-Eastern Alps: present configuration and future perspectives, ESC XXXII General Assembly, Montpellier, France, 6-10 September 2010, 2010.

BRTT Antelope software: http://brtt.com/software.html (last access 1 April 2014), 1995.

European Regional Development Fund (ERDF): http://ec.europa. eu/regional_policy/thefunds/regional/index_en.cfm (last access: 5 April 2013), 2000.

Horn, N., Pesaresi, D., Costa, G., and Živčić, M.: Testing the Antelope software suite to realize a distributed seismic database among Austria, Northeastern Italy and Slovenia, EGU General Assembly, Vienna, Austria, 15-20 April 2007, EGU2007-A03498, 2007.

Interreg IV Italia-Austria: http://www.interreg.net/ (last access 5 April 2013), 2007.

Progetto SeismoSAT: http://www.crs.inogs.it/seismosat/ (last access: 3 April 2013), 2012.

SEED Reference Manual Version 2.4: http://www.fdsn.org/seed manual/SEEDManual_V2.4.pdf (last access 1 April 20140, 2007. 